\title{
Methods and Tools for Designing a Multi-Service Platform for Agricultural Enterprises
}

\author{
Petr Skobelev, Igor Mayorov, Dmitry Novichkov, Elena Simonova
}

\begin{abstract}
The paper dwells on the problems of developing an internet platform for support of decision-making and production management for an agricultural enterprise. The described system is an open environment which is capable of integrating third-party services with the application-programming interface (API), each service being an autonomous software component (agent) with its own criteria and target. Thus, planning is done through continuous interaction of agents within the multi-service platform, using the knowledge base for storing various data on crops, such as conditions of crop growing, characteristics and peculiarities of crop production, pests, plant diseases, soil types and their specific features, technological processes (maps) for crop growing, application of fertilizers and plant protection products, crop production economy, classes of agricultural machines and equipment. Thus, the result of scheduling is the work plan for a given time horizon. On top of that, the paper describes the first prototypes of smart services and their interaction, as well as the next steps for future research.
\end{abstract}

Keywords: precision agriculture, agricultural management, decision-making support, multi-agent coordination, multi-service platform, ontology.

\section{INTRODUCTION}

Production processes in an agricultural enterprise are directly influenced by a great number of factors, so it is crucially important to take them into account during scheduling and management. Among these factors are the following: data on crop rotation, changes in chemical composition of soil, specific features of crop cultivation, and available machinery and materials. Apart from storing this data and providing access to it for specialists of agricultural enterprises, it is also critically important to use not only operational data, but also

Revised Manuscript Received on December 30, 2019.

* Correspondence Author

Petr Skobelev, Professor, Department of Electronic Systems and Information Security, Samara State Technical University, Samara, Russia. E-mail: skobelev.sstu@mail.ru

Igor Mayorov, Ph.D., Chief engineer, Institute for the Control of Complex Systems of Russian Academy of Sciences, Russian Federation, 443020 Samara, Sadovaya str., 61, imayorov@smartsolutions-123.ru

Dmitry Novichkov, Software developer, Aeropatrol, Ltd., Russian Federation, 443013 Samara, Moskovskoe shosse 17, Business center "Vertical", office 35, E-mail: novichkov@smartsolutions-123.ru

Elena Simonova*, Ph.D., Associate Professor, Department of Information Systems and Technologies, Samara National Research University, Samara, Russia. E-mail: simonova@smartsolutions-123.ru

(C) The Authors. Published by Blue Eyes Intelligence Engineering and Sciences Publication (BEIESP). This is an open access article under the CC BY-NC-ND license (http://creativecommons.org/licenses/by-nc-nd/4.0/) historical and methodological information for organizing automatic planning of production processes.

Besides, it is crucial to implement software tools for planning and managing processes. It can help improve the enterprise's key performance indicators, such as gross harvest per hectare and direct production costs.

For solving these issues, we propose a multi-service agricultural platform for planning processes based on ontological knowledge representation and multi-agent scheduling engine. Agriculture in general and crop production in particular are highly dependent on climatic conditions. Thus, many agricultural regions fall into the areas of risky farming. Moreover, annual losses due to unfavorable climatic conditions can sometimes sum up to hundreds of billions.

However, the following measures can prevent such losses and increase production efficiency:

- Tools for crop monitoring can provide timely assessment of crop condition, and help determine the best time for work execution and identify bottlenecks.

- Monitoring of production processes and machinery helps identify cases of technology violation and greatly reduce fuel costs. Moreover, accounting systems can reduce the time for operational management.

- Automatic planning of production operations for creating a work schedule and calculating requirements for fuel, lubricants, fertilizers and other materials for the entire production season. Methods of precision farming can reduce production costs by up to $20 \%$ and increase the yield by up to $30 \%$ for some crops [1].

Thanks to introducing information systems with smart technologies, agricultural production can reach a new technological level and producers can compete effectively in the local and international markets.

The platform can maximize employee discipline, reduce management complexity and labor intensity, as well as workload of managers and specialists. All of this can provide for strategic and operational planning of agricultural production.

The key goal of the platform will be to help users in solving the following crucially important tasks:

- Remote crop monitoring;

- Control of production resources and processes;

- Automatic planning of production;

- Increasing its efficiency. 


\section{Methods and Tools for Designing a Multi-Service Platform for Agricultural Enterprises}

\section{STATE OF THE ART}

Currently, multi-service platforms are developed for different industries, including agricultural production.

Thus, [2] describes Watson Decision Platform for agriculture by IBM which uses its most advanced capabilities in artificial intelligence (AI), analytics, IoT, cloud computing, and weather forecasting. Valuable information is extracted, and recommendations are automatically generated for agricultural producers.

Agroop, Portugal [3] is developing a big information platform and an IoT solution to help farmers produce more using less resources. It proposes a solution for crop monitoring, irrigation management, creating pest and disease alerts, risk prevention, analyzing enterprise data, sending and receiving recommendations.

Integral crop production management program ExactFarming Platform, Russia [4] provides a web-based service for farmers, agronomists and owners of agricultural enterprises for access to data about fields, weather, NDVI (Normalized Difference Vegetation Index), procurement records, availability of equipment, staff workload. crop rotation and history of field work.

Farmbrite, USA [5] provides software for managing agricultural production, including planning and task management, field mapping, field rotation, seed order evaluation system, harvest reports, online sales, equipment maintenance, revenue and expense control.

Agrivi, UK [6] proposes software with a powerful agricultural knowledge base. It helps farmers manage all the field work, finances, resource inventory, and workforce, detect pests and diseases, protect crops in a timely manner and receive information on production indicators.

Review [7] stresses the need for a wider use of new ICT (information and communication technologies), such as the Internet of Things, cloud computing and big data in the cyber-physical cycle of managing agricultural enterprises for Smart Farming, as well as introduction of robots and artificial intelligence.

[8] describes a smart and modern ICT-based approach to speed up the decision-making process for crop protection across large areas in India. The method is designed for identification of pests and timely implementation of measures to combat them in various agroecosystems of the country, which will minimize harvest losses. The easily-accessible pest control recommendations, specific to a particular farm, will provide advisory information on pests to the farming community on a massive scale.

However, these services are built as "monolithic" solutions, closed to third-party developers and embedded in existing solutions, i.e. cannot be offered as services and interact with other services, for example, to be associated with phases of plant development and make recommendations for further actions, as well as adjust the enterprise plans. Most of these systems perform accounting and advisory functions, although adaptive resource planning systems, including agent-based, are developed very actively for industrial production.

For example, in [9] "smart" production is described, which is able to adapt and change, in particular, by identifying opportunities for reconfiguring its behavior and functionality "on the fly", as well as by offering new, more adapted services. The paper presents an agent-based approach to reconfiguring services that allows users to dynamically identify reconfiguration capabilities and implement the best strategies for reconfiguring services on the fly. These features can help significantly increase production efficiency.

This paper develops the new concept of digital ecosystem an open, distributed, self-organizing "system of systems" of smart services that can autonomously resolve conflicts and coordinate individual behavior while solving complex tasks in a group. To implement such an ecosystem, it is proposed to apply the multi-agent architecture and collective decision-making in self-organizing networks of autonomous agents [10, 11].

The new-generation enterprise digital Platform is the basis for creating autonomous intelligent systems (AIS), i.e. "augmented intelligence" systems, working together with decision-makers, with further communication of tasks to employees and control of their execution.

The structure of such systems involves creation of diverse, relatively autonomous enterprise components, united in a single production system with a network structure with horizontal and vertical interactions of components that operate in a single information space of knowledge and data and can exchange information, services and resources [12].

A set of system services has been developed that are required for implementation of any production system, based on FIPA architecture services [13].

Basic system and application services are proposed that should provide the following:

- creation of a single information space of knowledge and data for a production system and mechanisms of its consistent use by all its components;

- effective mechanisms for planning the use of production system resources and their operational management in real time based on virtual market services;

- support for an expandable library of protocols and scripting mechanisms for various structured mechanisms of detecting patterns in accumulated data and for machine learning of decision-making mechanisms;

- support of logging services for work of system components, accumulation and analysis of data, as well as services of embedded mechanisms for detecting patterns in accumulated data and machine learning of decision-making mechanisms;

- connection of external services and resources, in particular, cloud services and sources of online information such as sensor networks.

Based on the created conceptual model, domain area services have been developed, including services for calculating percentage of crop sprouting using data from unmanned aerial vehicles, searching and determining the size of problem areas of inhomogeneous crop development using data on crop vegetation indices, etc.

\section{METHODOLOGY OF DEVELOPING A MULTI-SERVICE PLATFORM}

As shown above, the Platform is a set of smart services, in which integrations are possible through API.

Published By: 
This is what sets it apart from the traditional information systems and databases, as well as classical accounting systems.

\section{A. High-Level Architecture}

The platform will include new components: knowledge base and some new services for performing specific tasks. These services will interact with each other in order to reach a coordinated decision. Thus, degree of intellectuality of the resulting solution will be increased step by step.

All of the features will be available via the Platform web portal based on the SAAS (software as a service) model. Fig. 1 represents the high-level architecture of the Platform.

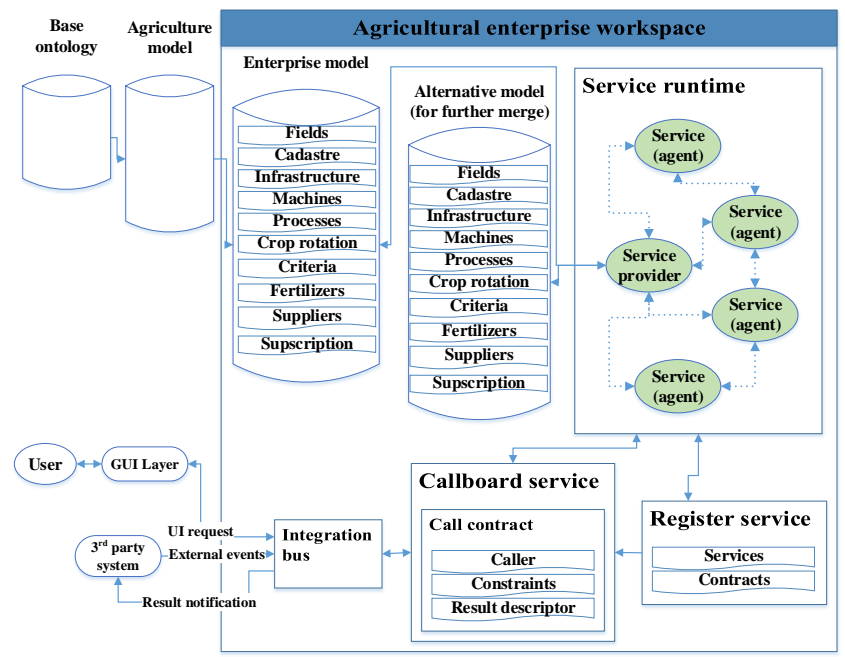

Fig. 1. High-level architecture of the Platform (Source: compiled by the authors)

The Platform consists of the following main components:

- Base ontology, which is a set of core concepts applicable to any domain.

- Agriculture model, which is a set of inherited from the base ontology concepts and specific for agriculture domain.

- Enterprise scene, which is a database of enterprise main assets, resources, suppliers, machines, objects, processes, criteria.

- Alternative scene(s), which is used by services to store intermediate planning results, data sets.

- Register service, which is the "yellow pages" of available services.

- Callboard service, which is used by services to interact with each other.

- Integration bus for interaction with external modules and systems.

- Service runtime, which is the main service environment as they work and negotiate.

\section{B. Knowledge Base}

One of the Platform's key components is the knowledge base. It consists of three elements: base ontology, agricultural model and enterprise scene. All the major platform services will use the knowledge base. The platform knowledge base contains specially structured information about a certain subject domain. The main purposes of the knowledge base are the following:

- Systematization and integration of knowledge. For example, what materials are required for tasks, what materials are purchased through procurement, and which ones are stored in the warehouse, what are results of tasks, etc.

- Improving the quality of planning by providing the knowledge. A multi-agent planning engine can obtain the necessary information from the knowledge base. At the same time, the extensible model of knowledge allows the agents to add new properties to the objects and determine relations between them, which should be taken into account next time during planning.

- Providing a knowledge-sharing environment for specialists of different subject domains in order to support formation of competences. Thus, community of experts can grow, so the knowledge base improves in quality.

The key element in the knowledge base is an ontology that describes domain concepts. Ontology defines the data structure used to describe information objects and solve business problems by services [14].

Among approaches to ontology design, it is possible to note the classical one, based on construction of ontology in accordance with the ontological analysis standard IDEF5, and the modern one, implying construction of web-ontologies in the context of Semantic Web.

Among methodologies and methods of constructing ontologies, the following can be mentioned:

- The CYC approach;

- SENSUS method;

- KACTUS method;

- The method of Uskold and King;

- On-To-Knowledge (OTK) methodology;

- METHONTOLOGY methodology;

- The methodology of Grüniger and Fox.

The above-mentioned methodologies have a number of general characteristics:

- Compilation of dictionary/ontological basis;

- Definition of links between concepts of an ontological basis;

- Encoding data through the toolkit.

The considered techniques can be divided according to the methods of their construction into several types:

- Techniques that allow reusing existing ontologies, thus making it possible to modify and expand the ontology used (KACTUS method);

- Techniques that allow users to merge several ontologies and knowledge sources into one object (SENSUS method);

- Methods that allow users to build ontologies, based on business processes of the specific domain (the method of Uskold and King, as well as methodology of Grüninger and Fox);

- Techniques that allow users to build an ontology based on knowledge of entities and their properties (the CYC method).

Based on the above-mentioned methods, our own approach to building a knowledge base was formulated, allowing the following:

- Reusing the concepts of other ontologies;

Published By: 
- Expanding the knowledge base by entering new object classes, relations, and attributes;

- Formalizing the subject domain for the needs of the scheduling engine, service or agent.

The main stages of creating an agricultural knowledge base are:

- Construction according to meta-ontology "Aristotle model", the main concepts of which are "Essence", "Object", "Class", "Ratio" and "Attribute".

- Construction of a unified (not domain-specific) ontology for scheduling services. This includes the following concepts: "Entity", “Task", "Resource", "Task result", “Order", "Service”, etc. (Fig. 2).

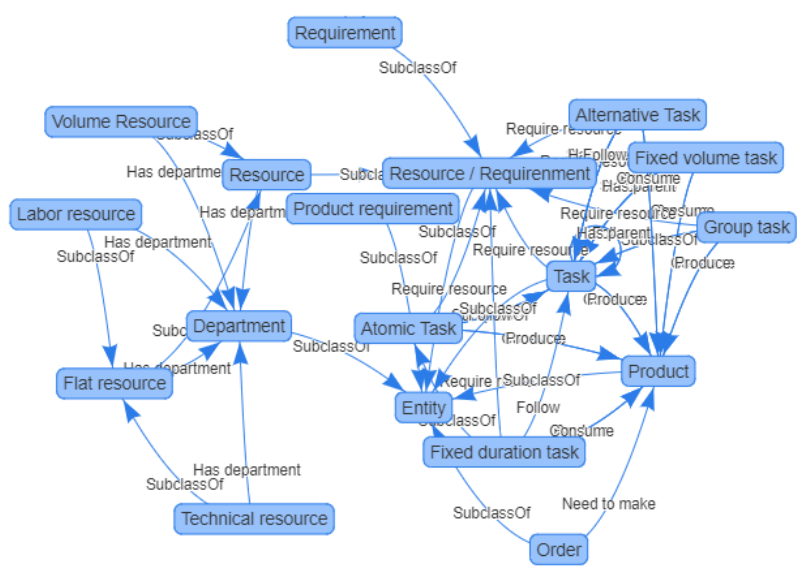

Fig. 2. Unified ontology for scheduling services (Source: compiled by the authors)

- Construction of domain-specific ontology, which contains definition of domain basic concepts and relations and are inherited from unified ontology at the same time. Thus, description of the world can be built not as a "closed" software model, which at each of the changes needs to be reprogrammed, but as an open model of physical/abstract entities, allowing users to model processes of their interaction.

- Construction of a domain model containing data, based on the previously defined ontological basis.

The overall purpose of developing and using ontologies is formalizing the subject domain in order to provide all the necessary data to the scheduling system. It is also important to do it at a certain level of abstraction. Thus, the described approach makes it possible to build smart planning systems, since it makes it possible to adjust planning to a certain degree without redesigning algorithms and reprogramming.

Based on this goal, the main criteria for ontology are:

- Transparency. The implied meaning of a certain term must be transmitted in a clear and unambiguous manner, excluding double interpretations.

- Connectivity. The ontology must be coherent and should allow for drawing conclusions that are consistent with original definitions of concepts, without causing contradictions.

- Extensibility. The ontology should allow for replenishing the knowledge base without affecting the information already available in it.

- Syntax-independent. Conceptualization should be specified at the level of knowledge as much as possible, independently of concept representation at the symbol level.

- Minimal basis and high expressiveness. The ontology should have a minimal basic set of concepts, but they should be enough to describe complex heterogeneous subject domains.

- Uniqueness. Each information object must have a unique identifier.

- Convenience for the user. The ontology should allow for expressing knowledge in the usual way for the user, to be understandable, foreseeable and coherent.

- Efficiency of machining. The ontology should be represented in the form that allows for efficient computer processing with different services (agents).

In addition, the following basic requirements are imposed on modern knowledge bases and information stored in them:

- Reliability of specific and generalized information available in the database.

- Relevance of information obtained with the knowledge base withdrawal rules.

- Verification of the knowledge base.

Knowledge bases are verified using semantic networks as a model of knowledge visualization. It is carried out on the basis of such operations as:

- Syntax check operations;

- Control of completeness;

- Control of looping in relations;

- Control of incorrect data types;

- Control of availability of range constraints for all attributes and relation types;

- Control of availability of base (inherited) classes for all domain-specific classes.

Hereby, ontology describes the basic concepts of the domain. For agriculture domain, such description should include the following [15]:

- Data about crops and their varieties;

- Indicators of productivity for crop varieties in different growth conditions;

- Data about pests and plant diseases;

- Data on types and characteristics of soils, as well as climatic zones;

- Technological maps of crop cultivation;

- Rules of permissibility of crop rotation options;

- Data on biopreparations and fertilizers;

- Data on agricultural machinery and equipment;

- Key indicators of crop production efficiency.

Knowledge bases with ontologies contain objects, in the form of interrelated concepts, as well as their attributes (descriptions) and main interdependencies (relations) between them. Classes of concepts form a hierarchy based on inheritance.

Such an ontological approach to knowledge storage allows for describing any heterogeneous subject domain, however complex it may be. 
It is possible to formalize specific domain knowledge in the form convenient for computer processing. Thus, knowledge can also be separated from the source code.

The knowledge base is developed according to the following ontological model [15]:

- There are objects that have properties and are characterized by states (for example, a field, a harvester, a job).

- Properties express the abilities of objects for interaction based on the rules of the world (for example, a harvester "has" the property "bunker capacity").

- Relations can be of a different matter: structural, functional, temporal or any other (for example, a harvester "performs" a harvesting job).

- Conditions for performing an action, are set by properties and relations (for example, all "performing" resources should be used for a harvesting job).

- Actions (processes) change the states of objects, their properties and relations (for example, the action "harvesting" changes the state of the object "field" from "sown" to "harvested").

- Properties, relations and actions are characterized by attribute values (for example, the attribute of a grain storage is "Current available volume").

- Attributes of an object or relation can be either qualitative or quantitative (for example, "Current available volume" is 30 tons).

- Rules represent generalized concepts for formalized conditions in the form of "if-then" (predicates) and utterances (statements, axioms, facts).

The ultimate purpose of developing and using ontologies is to provide support for knowledge accumulation, separation and reuse. Knowledge should be further available for smart planning services of an agricultural enterprise.

\section{SMART SERVICES}

Thus, an extendable set of separate services (agents) forms the most realistic digital model of an agricultural enterprise. Each of these services represents one or another aspect of crop production (Fig. 3).

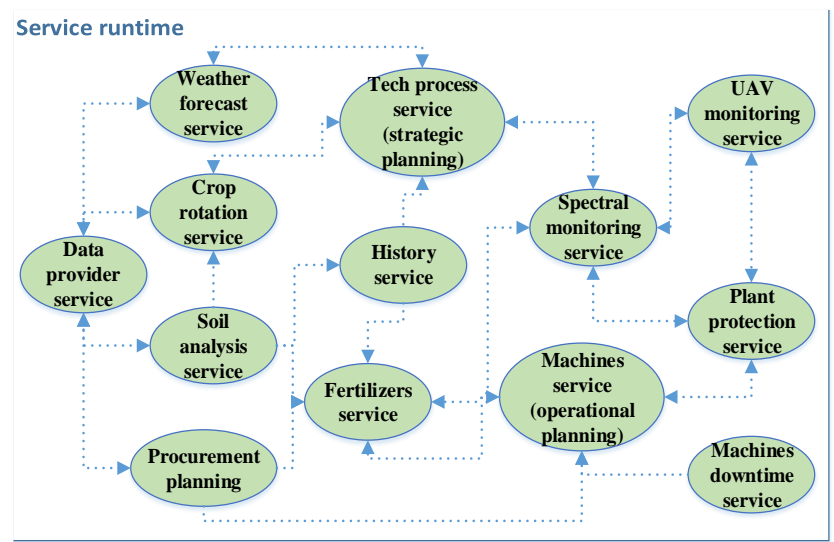

Fig. 3. Base set of Platform services (Source: compiled by the authors)

These services can detect problems and develop plans for their solution, at the same time reducing the time spent and resources used [16]. For example, a crop monitoring service (agent) can automatically detect deviations in development of a certain crop on a satellite image and outline the problem area. Then the planning service (agent) calculates costs for selective cultivation of the detected problem area, using data from the knowledge base in order to formulate work tasks and identify the necessary resources. Moreover, other connected services can also take part in this process. For example, the weather service (agent) can help determine the best time for the proposed cultivations, whereas the machinery service (agent) can provide data on available machinery and employees.

During the first stage of developing the platform, the main input data for software services is information from the database. Later, a knowledge base will be added as a separate service, containing information on production processes, agricultural technologies, relations between processes and internal rules. Smart services should take into account not only the actual production information from the database, but also data from the knowledge base. Thus, the level of intellectualization in management of agricultural production can be greatly increased.

Generally, architecture of multi-service platform should allow for adding new services without having to stop the work of its other parts and without redesign of the platform core. Here, essential is the possibility to connect third-party services using the proposed API.

Each service is an autonomous, constantly working software agent, continuously striving to reach its goals. These services are based on multi-agent technology and can interact with each other via a common set of protocols [16]. Such an approach makes it possible to use several services jointly with the ability to interact with each other in the interests of the agricultural enterprise. It is also possible to add new smart services during development in order to support new types of resources or operations.

Development of services based on multi-agent principles helps implement distribution of resources and control of their use within separate tasks solved. For example, distribution of machinery among the fields takes into account various criteria of work importance and availability of machinery units.

Herewith, services interact with each other based on the principles of multi-agent Internet of Things (IoT) [17, 18]. Thus, agents representing certain real-world objects (fields, fertilizers, technological operations or machinery) react to emerging external events or changes in the states of their resources and then start interacting with each other in order to find a solution to the problem and make their common benefit the highest possible. To reach such a decision, agents communicate by suggesting their own options and considering variants received from other agents. They can also make adjustments to their decisions in response to new events and solutions offered by other agents. Such chains of coordinated interrelated changes bring a high level of intelligence to the developed solutions. Moreover, such negotiation is carried out in real time, responding to emerging events on the fly. 
User interaction is supported by the web portal. Its graphic interface reflects data on the current states of different crops, infrastructure facilities, and machinery. Users can compare planned and actual performance indicators, which are found in separate forms. Thus, the platform is designed for practical use of employees and owners of agricultural enterprises.

\section{RESULTS AND DISCUSSION}

As discussed above, actual data on the state of production is of crucial importance for effective management of agricultural enterprises. It helps managers in forming the most accurate work plans, which can contribute to achievement of key performance indicators (criteria). such as yield (productivity), production costs and possible deviations from technology. Sometimes users require plans for achieving other goals, such as minimizing the use of fertilizers, while maximizing yield, for example. In other cases, users may want to set some other additional planning constraints or rules.

Multi-agent technology makes it possible to successfully make plans in conditions of high uncertainty with several simultaneously operating criteria. Initial data can be found in the accounting system, while rules, limitations, logics and other specific features of planning can be described in the knowledge base.

In multi-agent planning, each of the agents has its own performance criteria (Table 1).

Table I: Agent classes

\begin{tabular}{|c|c|}
\hline Agent Type & Functions and Goals \\
\hline Crop rotation agent & $\begin{array}{c}\text { Offers an option of crops to } \\
\text { the fields for the next } \\
\text { production season }\end{array}$ \\
\hline Chief agronomist agent & $\begin{array}{l}\text { Looks at the proposed } \\
\text { options for crop rotation } \\
\text { plan, looks through the } \\
\text { problem areas }\end{array}$ \\
\hline $\begin{array}{c}\text { Agent of technological } \\
\text { process }\end{array}$ & $\begin{array}{l}\text { Reviews the crop rotation } \\
\text { plan and offers options for } \\
\text { suitable technological maps } \\
\text { for crops }\end{array}$ \\
\hline $\begin{array}{c}\text { Unmanned Aerial } \\
\text { Vehicle agent }\end{array}$ & $\begin{array}{c}\text { Plans detailed inspections of } \\
\text { crops with UAVs }\end{array}$ \\
\hline $\begin{array}{c}\text { Fertilizer and protection } \\
\text { agent }\end{array}$ & $\begin{array}{l}\text { Assesses the problems and } \\
\text { offers cultivation options }\end{array}$ \\
\hline Machine agent & $\begin{array}{l}\text { Schedules cultivation work } \\
\text { tasks }\end{array}$ \\
\hline Monitoring agent & $\begin{array}{c}\text { Analyzes images from } \\
\text { satellites, calculates the } \\
\text { values of vegetation indexes } \\
\text {, analyzes the crop condition, } \\
\text { performs automatic search } \\
\text { for problem zones on fields }\end{array}$ \\
\hline
\end{tabular}

The simplest workflow of planning can be described as the following:

- The crop rotation agent (service) offers an option of crops to the fields for the next production season based on historical data, crop rotation rules, information on resource stocks, weather forecasts, data on stock quotes by crops.

- The chief agronomist looks at the proposed options for crop rotation plan, adjusts and approves the option in a dialogue with the crop rotation agent (service).
- The agent (service) of technological process reviews the crop rotation plan along with data from the knowledge base and offers options for suitable technological maps for crops, as well as options for work tasks scheduled by dates.

- The agent (service) of crop monitoring analyzes images from satellites, calculates the values of vegetation indexes, performs automatic search for problem zones on fields.

- The chief agronomist looks through the problem areas, and chooses the areas to be examined in detail by unmanned vehicles.

- The Unmanned Aerial Vehicle (UAV) agent (service) plans detailed inspections of crops with UAVs and proposes a set of tasks for the staff and a flight plan for the UAV.

- The fertilizer and protection agent (service) assesses the problems and offers cultivation options.

- The machine agent (service) schedules cultivation work tasks coordinated with the general plan of the farm, resources, deadlines and other restrictions.

- The monitoring agent (service) continues analyzing the crop condition and process loops.

The resulting plan is formed through mutual negotiations of agents striving to reach a compromise variant of the plan. It must at least partially satisfy each agent, while also satisfying the entire system as much as possible.

However, let us consider detailed option of planning process for the proposed high-level architecture:

- There is a Crop Rotation Planning Service (CRPS) and a Technological Map Planning Service (TMPS) among other services of the Platform.

- The TMPS requests a crop rotation plan (3 different options) and places this request at Callboard service (CS) with timeout limit of 60 seconds.

- The SRPS looks at the CS board, finds the request for a crop rotation plan and commits to this task.

- The SRPS has business logic and needs three argument values to propose collection of results. For each farm field it is necessary to know the following: 1. info on soil agrochemicals, 2 . history of crop rotation, 3. rules of crop rotation.

- The SRPS looks at the internal context (its local database) for the necessary data (arguments), which can be the necessary input parameters for the task.

- The SRPS finds data of crop rotation rules for one parameter of three in its local database.

- The SRPS forms two separate requests for the remaining necessary two parameters and places them in the CS bulletin.

- The data provider service (DPS) reviews requests in the CS bulletin, sees 2 new requests available and suitable for him, and commits to these tasks.

- The soil agrochemical analysis service (SACAS) looks through the CS bulletin, sees a new request for agrochemical analysis and commits to this task.

- The DPS and SACAS perform requests and provide results to the CS. The CS notifies the SRPS every time the new result is available. 
- The SRPS takes available results and has all three necessary data parameters, and there are even two options for the agrochemical analysis parameter.

- The SRPS produces crop rotation variants based on the available data and proposes the result to CS.

- The CS notifies the TMPS about the new result available. The TMPS receives the results.

In conditions of high dynamics of the real world, new events are constantly occurring, so the planning process must be adaptive. Thus, the formed harvesting plans should be promptly revised and rebuilt. The multi-agent planning engine strives to achieve the target indicators and use data from the knowledge base.

Ontological approach to knowledge storage together with multi-agent technology automatically create work plans, taking into account all the rules and limitations described in the knowledge base.

Today the first prototype of the solution is designed and is currently under testing for Peschanokopskaya Agro Group in Rostov region of Russia, which has crop fields with more than 30000 ha. The use of the Multi-Service Platform for agricultural enterprises has reduced the cost of fuel (10\%), fertilizers (20\%), plant protection product (20\%) and seeds (10\%) through continuous operational monitoring of fields, the timely provision of information for management needs and increasing efficiency in decision-making (Table 2).

Table II: Reducing of the production costs through the use of Multi-Service Platform

\begin{tabular}{|c|c|c|}
\hline \multirow{2}{*}{ Materials } & \multicolumn{2}{|c|}{ Cost, RUR } \\
\cline { 2 - 3 } & Before use & After use \\
\hline Fuel & 10000000 & 9000000 \\
\hline Fertilizers & 39760000 & 31808000 \\
\hline Plant protection product & 26900000 & 21520000 \\
\hline Seeds & 4000000 & 3600000 \\
\hline
\end{tabular}

Automation of the planning process significantly reduces the time spent on making decisions by managers. It also guarantees that all the factors and peculiarities of production processes are taken into account, avoiding human errors, predicting the financial result, and increasing production efficiency of an agricultural enterprise.

\section{CONCLUSION}

As shown above, agriculture can be characterized by a high level of uncertainty and a great number of factors affecting production efficiency. The proposed multi-service web-based platform can help production processes in an agricultural enterprises reach a new technological level, since it provides tools for management, operational control, planning and forecasting.

The described approach shows the following advantages:

- Bringing automation to decision-making processes.

- Improving planning quality thanks to knowledge bases.

- Adaptively adjusting work plans in response to new events.

- Tools for modelling different scenarios and their financial results.

- Proposing tools for developing expert community.

On top of that, the described solutions can facilitate development of new software tools for managing agricultural production. Reducing labor intensity of developing and maintaining complex smart systems is very important, and applying knowledge bases in such systems can greatly reduce development time and cost for end users.

\section{ACKNOWLEDGMENT}

The work was supported by the Ministry of Education and Science of the Russian Federation in the framework of contract agreement №14.574.21.0183 - the unique ID number is RFMEFI57417X0183.

\section{REFERENCES}

1. Precision agriculture: an opportunity for EU farmers - potentia support with the CAP 2014-2020 [European Parliament's Committee on Agriculture and Rural Development] [Online]. Available: $<$ http://www.europarl.europa.eu/thinktank/en/document.html?referenc e=IPOL-AGRI_NT(2014)529049> [Accessed: 18 October 2019]

2. Smarter Farms: Watson Decision Platform for Agriculture [Online]. IBM. Available: <https://www.ibm.com/blogs/research/2018/09/smarter-farms-agricult ure/> [Accessed: 12 October 2019]

3. AGROOP [Online] October 2019]

4. ExactFarming [Accessed:12

/ru>/ [Accessed: 20 October 2019]

5. Farmbrite [Online]. Available: <https://www.farmbrite.com/>. [Accessed: 20 October 2019]

6. Agrivi [Online]. Available: <https://agrivi.com/en>. [Accessed: 21 October 2019]

7. Sjaak Wolfert, Lan Ge, Cor Verdouwa, Marc-Jeroen Bogaardt, "Big Data in Smart Farming - A review," Agricultural Systems, No. 153, pp. 69-80, 2017.

8. Surender Kumar Singh, “A smart precision plant protection technique based upon information and communication technologies for field crops in India for wide-area implementation," Journal of Applied and Natural Science, Vol. 10, No.1, pp. 262- 265, 2018.

9. N. Rodrigues, P. Leitão, and E. Oliveira, “An Agent-Based Approach for the Dynamic and Decentralized Service Reconfiguration in Collaborative Production Scenarios (Book style with paper title and editor)," in LNAI 10444, Vladimír Mařík et al, Eds. Switzerland AG. Springer, 2017, pp. 140-154.

10. M. Wooldridge, An Introduction to Multi-Agent Systems (Book style). London: John Wiley \& Sons, 2009, 368 p.

11. J. Müller and K. Fisher, "Application Impact of Multi-Agent Systems and Technologies: A Survey (Book style with paper title and editor)," in Agent-Oriented Software Engineering, O. Shehory, A. Sturm, Eds. Berlin: Springer, 2013, pp. 1-26.

12. Enterprise Interoperability: Smart Services and Business Impact of Etnterprise Interoperability. M. Zelm, F.-W. Jaekel, G. Doumeingts, M. Wollschlaege, Eds. London: John Wiley \& Sons, 2018, 496 p.

13. FIPA Abstract Architecture Specification, [Online]. FIPA. Available: <http://www.fipa.org/specs/fipa00001/SC00001L.html>. [Accessed: 22 October 2019]

14. Handbook on Ontologies. S. Staab, R. Studer, Eds. Berlin: Springer, 2009, 811 p.

P. O. Skobelev, D. S. Budaev, G. Yu. Voshchuk, A. N. Mochalkin, S. V. Susarev, N. G. Gubanov, "Planning of production processes for agricultural enterprises using joint competences of university and IT company in development of knowledge bases," in Proceeding of 2017 IEEE VI Forum Strategic Partnership of Universities and Enterprises of Hi-Tech Branches (Science. Education. Innovations) (SPUE), 15-17 Nov. 2017, St. Petersburg, Russia, IEEE Xplore, Vol. 2018- January, 3, pp. 141-143.

15. P. O. Skobelev, D. S. Budaev, G. Yu. Voshchuk, A. N. Mochalkin, S V. Susarev, N. G. Gubanov, "Designing a multi-service internet platform for managing an agricultural enterprise: Searching for an innovative solution during joint work of a university and an IT company," in Proceeding of 2017 IEEE VI Forum Strategic Partnership of Universities and Enterprises of Hi-Tech Branches (Science. Education. Innovations) (SPUE), 15-17 Nov. 2017, St Petersburg, Russia, IEEE Xplore, Vol. 2018 - January, 3, pp. 144-146. 
16. V. Gorodetsky," Internet of Agents: From Set of Autonomous Agents to Network Object," in IoA'17 (Book style with paper title and editor), Saad Alqithami, Marco Lutzenberger, Eds. Berlin: Springer, 2017, pp. $1-17$.

17. S. Greengard, The Internet of Things (Book style). London: MIT Press, 2015, 230 p.

\section{AUTHORS PROFILE}

Petr Skobelev is Dr.Eng. Science, Professor of Samara State Technical University, Russia. He graduated from Samara Aerospace University in 1983. He obtained a PhD degree in Functional Programming Languages and Artificial Intelligence for Aerospace Applications in 1986 and the Professor degree in Multi-Agent Systems for Real-time Resource Management in 2003 at the Institute for Control of Complex Systems of the Russian Academy of Sciences. Areas of his scientific interests include multi-agent technology, distributed intelligence, collective management, real-time logistics. Prof. Skobelev is the founder of the Group of companies "Knowledge Genesis" in Moscow, Russia, which includes the leading Software Engineering Company "Smart Solutions" - one of the most innovative Russian tech companies, fully focused on developing multi-agent systems. Besides, he is a member of the Russian Association for Artificial Intelligence and a member of the IEEE International Committee for Industrial Agents. Prof. Skobelev is the head of Laboratory of Intelligent Systems and Technologies at the Institute for the Control of Complex Systems of Russian Academy of Sciences, Professor at Samara National Research University and Head of Department of Electronic Systems and Information Security at Samara Technical University. The list of his publications includes more than 400 papers in the following areas: theory of complex adaptive systems, new approaches to enterprise resource management, emergent intelligence, multi-agent technology, knowledge bases, systems of systems, intelligent Internet of people and things (Internet of agents), and digital platforms for creating eco-systems of smart services.

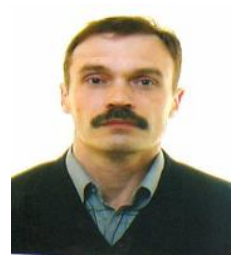

Igor Mayorov is Ph.D., Chief Engineer of Institute for the Control of Complex Systems of Russian Academy of Sciences. Head of Department for Development of Mathematical Models, Methods, and Algorithms at Software Engineering Company "Smart Solutions". He graduated from the Physics Department of Samara State University in 1989. In 2017, he obtained his PhD degree.

Areas of his scientific interests are artificial intelligence systems, multi-agent systems, optimization theory, discrete mathematics. He is the author of more than 80 publications in Russian and foreign journals on management of complex systems, multi-agent systems, and real-time modeling.

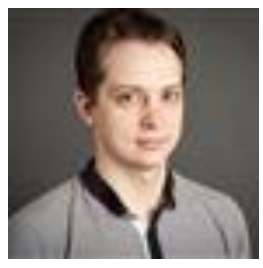

Dmitry Novichkov is a Software developer of Aeropatrol, Ltd., Russia. In 2011, he graduated from Samara State Technical University with a degree in Information Technology. He is the author of 6 scientific publications in Russian and foreign journals. The area of his scientific interests is development of smart systems for management of mobile resources based on multi-agent technology.

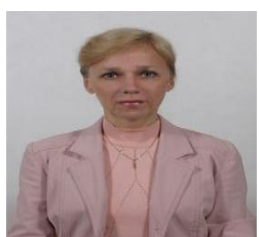

Elena Simonova is Ph.D., Associate Professor of Samara National Research University, Associate Professor of Department of Information Systems and Technologies at Samara National Research University, and Leading Analyst at Software Engineering Company "Smart Solutions". In 1985 she graduated from Samara Aerospace University with a degree in Automated Control Systems. In 1994 she obtained her $\mathrm{PhD}$ degree. She is the author of about 300 scientific publications in Russian and foreign journals. The area of her scientific interests is development of smart resource management systems based on multi-agent technology and ontological representation of knowledge. 